\title{
Influence of MgO Containing Strontium on the Structure of \\ Ceramic Film Formed on Grain Oriented Silicon Steel Surface
}

\author{
Daniela C. Leite Vasconcelos ${ }^{\mathrm{a}}$, Maria das Graças M.M. Cesar ${ }^{\mathrm{a}}$, \\ Marco Antônio da Cunha ${ }^{\text {a }}$,Wander L. Vasconcelos ${ }^{b}$ \\ ${ }^{a}$ Centro de Pesquisa e Desenvolvimento, ACESITA \\ ${ }^{\mathrm{b}}$ Departamento de Engenharia Metalúrgica e de Materiais, UFMG
}

Received: August 15, 1998; Revised: March 30, 1999

\begin{abstract}
The oxide layer formed on the surface of a grain oriented silicon steel was characterized by SEM and EDS. 3\% Si steel substrates were coated by two types of slurries: one formed by $\mathrm{MgO}$ and water and other formed by $\mathrm{MgO}$, water and $\mathrm{SrSO}_{4}$. The ceramic films were evaluated by SEM, EDS and $\mathrm{X}$-ray diffraction. Depth profiles of $\mathrm{Fe}, \mathrm{Si}$ and $\mathrm{Mg}$ were obtained by GDS. The magnetic core losses (at $1.7 \mathrm{Tesla}, 60 \mathrm{~Hz}$ ) of the coated steel samples were evaluated as well. The use of $\mathrm{MgO}$ containing strontium reduced the volume fraction of forsterite particles beneath the outermost ceramic layer. It was observed a reduced magnetic core loss with the use of the slurry with $\mathrm{MgO}$ containing strontium.
\end{abstract}

Keywords: ceramic film, forsterite particles, grain oriented silicon steel, magnetic core loss

\section{Introduction}

The grain oriented silicon steel has been used as a magnetic core material of electrical equipment and is required to have low core loss, high permeability and proper dielectric coating ${ }^{1,2}$.

In order to present low core loss and high magnetic permeability the silicon steel must develop during the secondary recrystalization (with the aid of $\mathrm{MnS}$ as an inhibitor) grains with a $\{110\}<001>$ (Goss) orientation ${ }^{1,3}$.

To avoid the coil laps from sticking during the final annealing and to provide good dielectric properties the decarburized silicon steel is coated with an annealing separator. The coating is deposited as magnesia slurry. The ceramic film (forsterite) is formed from a reaction between the steel surface and the magnesia. Additives have been added to the magnesia to provide stabilization of the secondary recrystalization process and also to provide a stable formation of forsterite $e^{4,5}$.

The objective of this work is to evaluate the influence of a $\mathrm{MgO}$ containing $1 \% \mathrm{Sr}$ (as $\mathrm{SrSO}_{4}$ ) on the structure of the ceramic film formed on the surface of a grain oriented silicon steel.

\section{Experimental}

The substrates used in this work were silicon steel samples supplied by Acesita SA and obtained just after the decarburization. They were coated with slurries kept at $5{ }^{\circ} \mathrm{C}$. One slurry was prepared with $10 \% \mathrm{MgO}$ and another with $10 \% \mathrm{MgO}+1 \% \mathrm{Sr}$ (added as $\mathrm{SrSO}_{4}$ and calculated as a function of the $\mathrm{MgO}$ weight). The coated samples were heat treated up to $1200{ }^{\circ} \mathrm{C}$ for $15 \mathrm{~h}$ in a hydrogen atmosphere.

The surfaces of the steel substrate and coated steel sheets were characterized by SEM (Philips XL30) and EDS (EDAX-DX4). The coated steel samples were also characterized by X-ray diffraction (Rigaku-Geiger flex) and glow discharge spectrometry - GDS (depth resolved, radio frequency glow discharge atomic spectrometry, with a Jobin Yvon 5000RF).

The core losses measurements were conducted under an alternating magnetic field of 1.7 Tesla at $60 \mathrm{~Hz}$ by SST (Single Sheet Tester) testing method with a Brockhaus Messtechnik equipment.

\section{Results and Discussion}

During the decarburization stage a layer of oxides with $2.1 \pm 0.5 \mu \mathrm{m}$ was formed on the steel sheet surface, as 
shown by the cross-section photo in Fig. 1a. That oxide layer was identified as amorphous silica $\left(\mathrm{SiO}_{2}\right)$ and fayalite $\left(\mathrm{Fe}_{2} \mathrm{SiO}_{4}\right)^{6}$. Considering the elements $\mathrm{Fe}, \mathrm{Si}$ and $\mathrm{O}$ four regions were identified by EDS, which are shown in Fig. 1a. Point 1 (Fig. 1a) refers to a typical chemical composi- tion of the steel sheet, with around $2.5 \pm 0.5(\mathrm{wt}) \% \mathrm{Si}$, as shown by the EDS spectra in Fig. 1b. (All the results of EDS composition used in this work are expressed in weight percent.) Figure 1c is related to the light grey oxide layers closer to the outermost surface, represented by point 2 , with

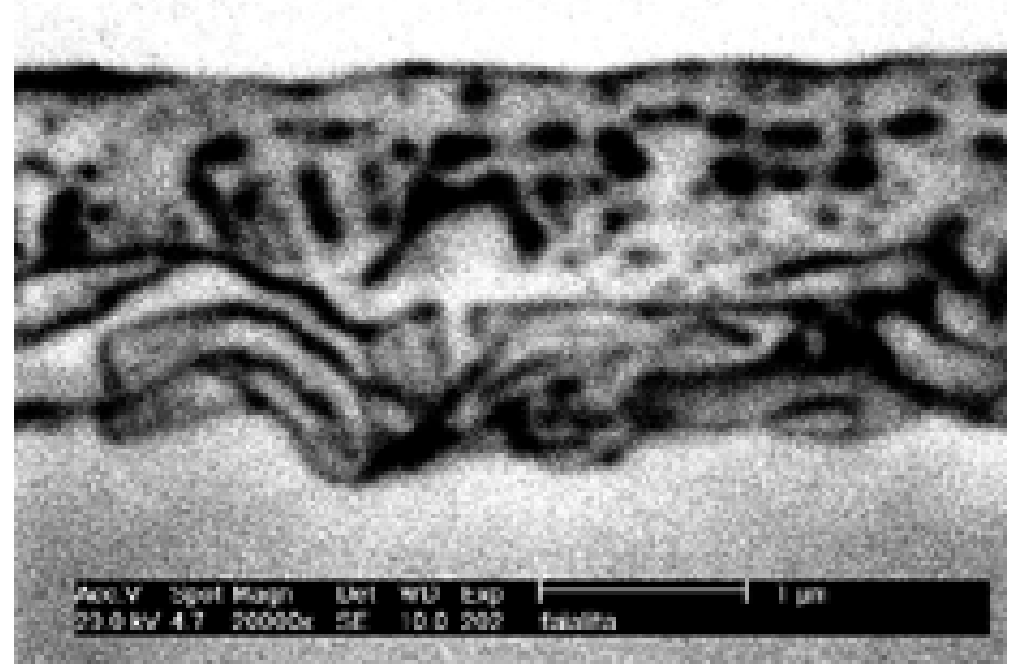

(a)

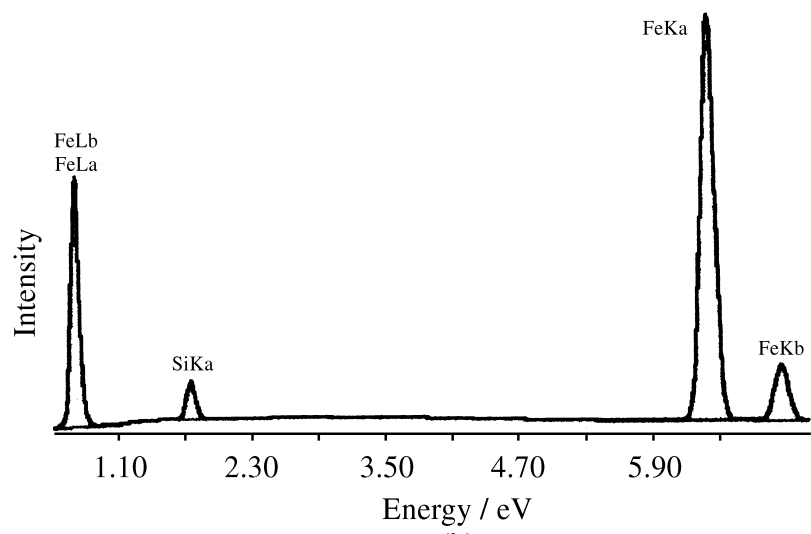

(b)



(d)

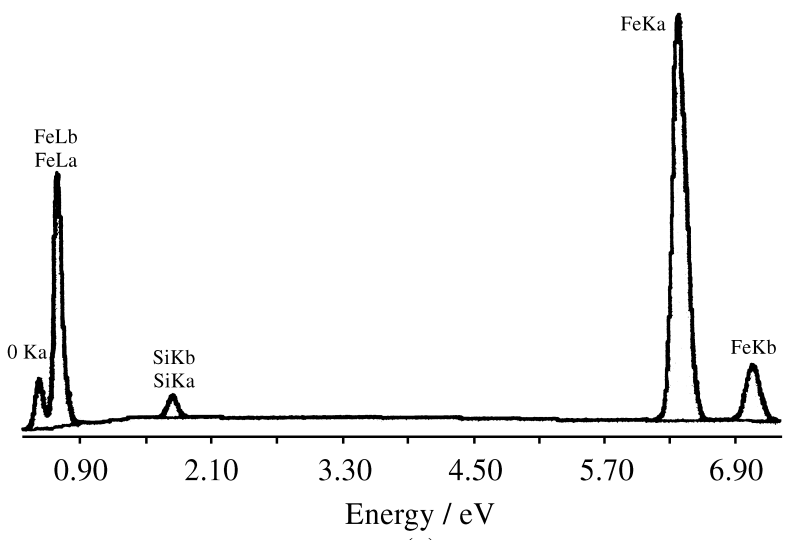

(c)

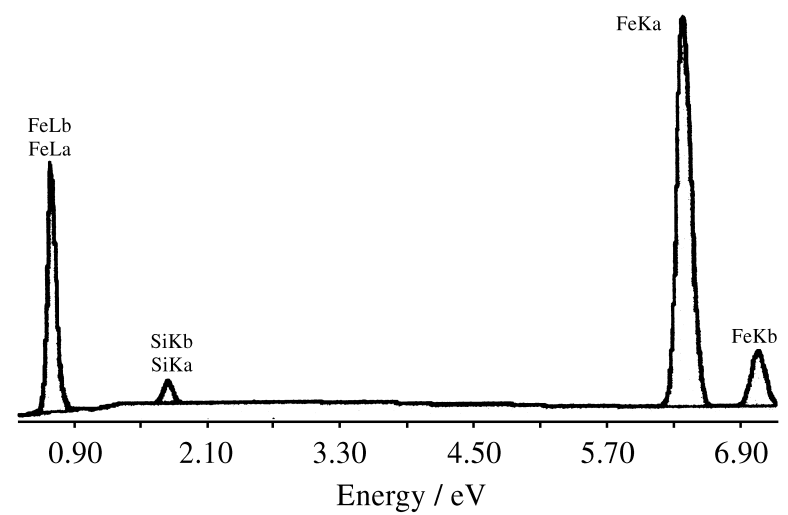

(e)

Figure 1. Typical oxide layer formed on the surface of the steel substrate. (a) 20000X; EDS spectrum for (b) point 1; (c) point 2; (d) point 3 and (e) point 4. 
$1.9 \pm 0.4 \% \mathrm{Si}$. The dark regions shown by point 3 presented $5.8 \pm 1.3 \% \mathrm{Si}$, as shown in Fig. 1d. The light grey regions closer to the outermost surface present smaller Si content than the steel sheet and $\mathrm{O}$ content smaller than the darker regions and are associated with fayalite. The dark regions present higher $\mathrm{Si}$ and $\mathrm{O}$ contents and are associated with
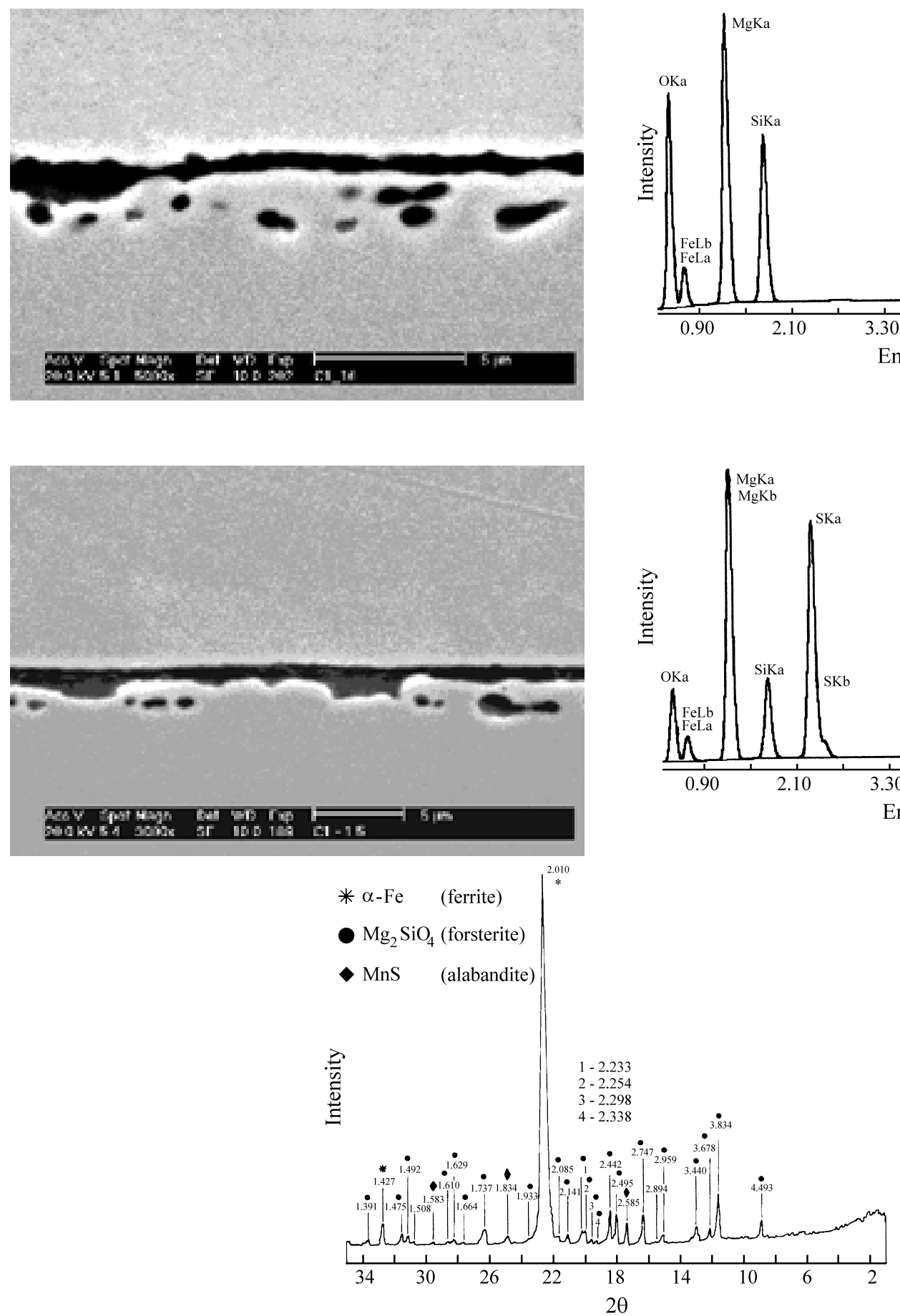

(e) the presence of silica. At the inner parts of the surface layer, the light grey regions represented by point 4 (EDS spectrum shown in Fig. 1e) present $1.8 \pm 0.3 \% \mathrm{Si}$, no oxygen and may be associated with metallic Fe.

After the final annealing at $1200{ }^{\circ} \mathrm{C}$ for $15 \mathrm{~h}$, the impurities elimination, the secondary recrystalization and

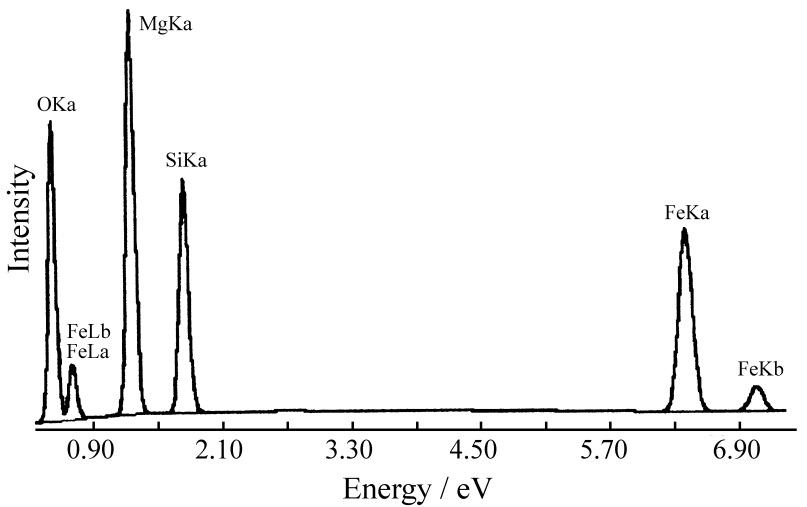

(b)

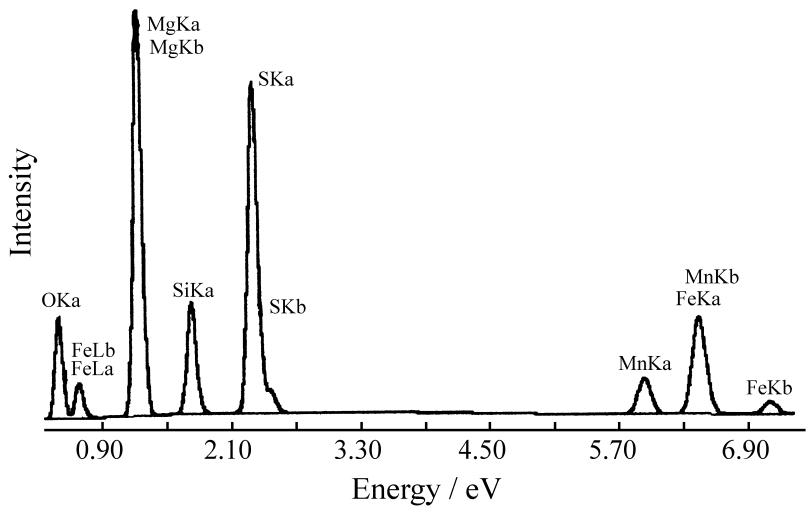

(d)

Figure 2. Typical oxide layer formed with the $\mathrm{MgO}$ slurry deposition. (a) 5000X. (b) EDS spectrum obtained for the continuous layer and for the dark particles of Fig. 2a; (c) 3000 X; (d) EDS spectrum for point 1; (e) X-ray diffraction spectrum of the ceramic film. 
Table 1. EDS data for the film formed by $\mathrm{MgO}$.

\begin{tabular}{lccc}
\hline & $\% \mathrm{O}$ & $\% \mathrm{Mg}$ & $\% \mathrm{Si}$ \\
\hline Continuous layer & 26 & 27 & 15 \\
dark regions at the sub-layer & 19 & 21 & 11 \\
\hline
\end{tabular}
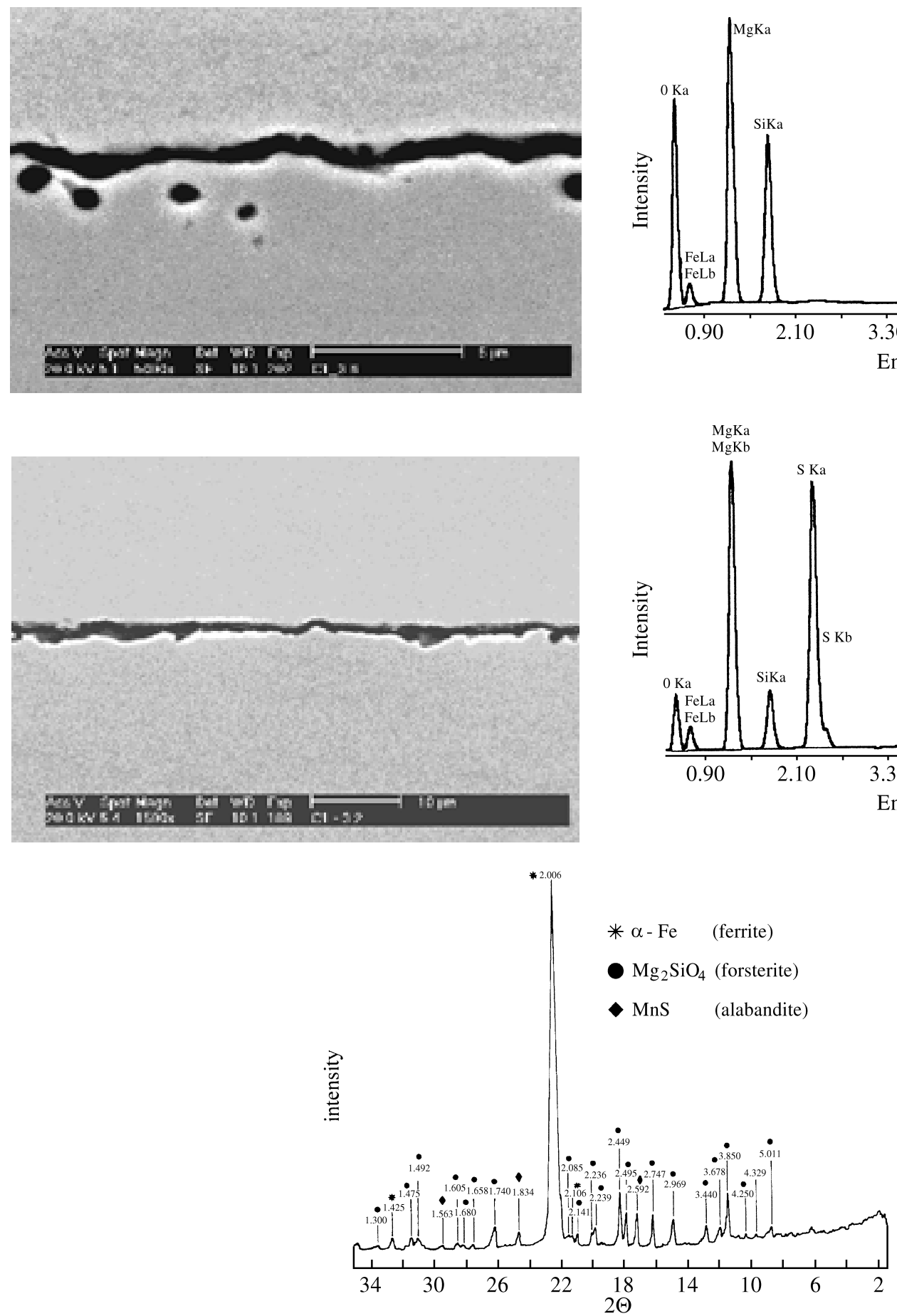

(e)
Table 2. EDS data for the film formed by $\mathrm{MgO}+1 \% \mathrm{Sr}$.

\begin{tabular}{lccc}
\hline & $\% \mathrm{O}$ & $\% \mathrm{Mg}$ & $\% \mathrm{Si}$ \\
\hline continuous layer & 30 & 28 & 17 \\
dark regions at the sub-layer & 24 & 24 & 14 \\
\hline
\end{tabular}

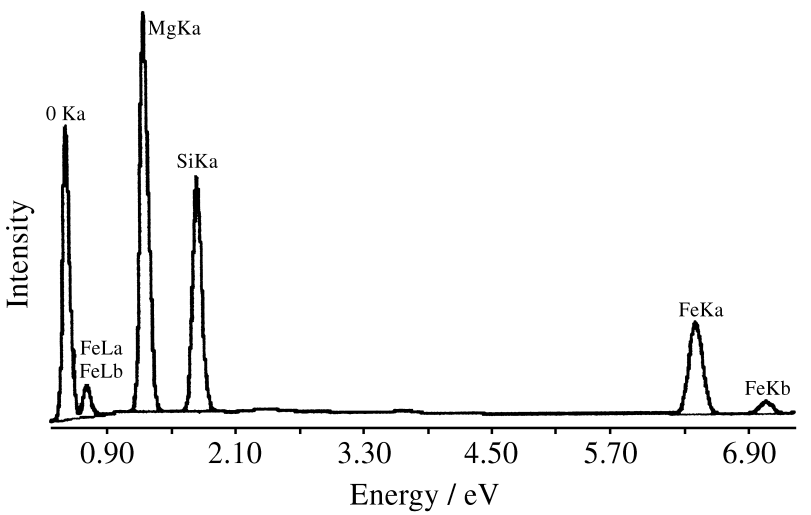

(b)



(d)

Figure 3. Typical oxide layer formed with the $\mathrm{MgO}+1 \% \mathrm{Sr}$ slurry deposition. (a) 5000X. (b) EDS spectrum obtained for the continuous layer; (c) $1500 \mathrm{X}$; (d) EDS spectrum for point 1; (e) X-ray diffraction spectrum of the ceramic film. 
the formation of the ceramic film on the sheet surface occurred.

Figure 2a presents a typical morphology of the ceramic film formed after the $\mathrm{MgO}$ slurry deposition. The continuous layer is relatively richer in oxygen, magnesium and silicon than the dark regions at the sub-layer, as shown in Table 1.

While the stoichiometric ratios of the forsterite $\left(\mathrm{Mg}_{2} \mathrm{SiO}_{4}\right)$ components are $\mathrm{Mg} / \mathrm{Si}=1.7$ and $\mathrm{Mg} / \mathrm{O}=0.8$ (in weight), the measured ratios were $\mathrm{Mg} / \mathrm{Si}=1.8$ and $\mathrm{Mg} / \mathrm{O}=1.0$ for the continuous layer and $\mathrm{Mg} / \mathrm{Si}=1.9$ and $\mathrm{Mg} / \mathrm{O}=1.1$ for the dark regions at the sub-layer. These facts strongly suggest that the dark particles and the surface layer are composed of forsterite. Figure $2 \mathrm{~b}$ shows the EDS spectrum obtained for the continuous layer. Another typical morphology of the film formed with $\mathrm{MgO}$ is shown in Fig. $2 \mathrm{c}$, where the continuous layer presents some thicker regions. In these regions (point 1 and 2 in Fig. 2c), one can find, besides the elements of the forsterite, the presence of $\mathrm{S}$ and $\mathrm{Mn}$, which are used as grain growth inhibitors. The EDS analysis of points 1 and 2 are very similar and indicate the presence of $17 \% \mathrm{O}, 29 \% \mathrm{Mg}, 8 \% \mathrm{Si}, 20 \% \mathrm{~S}$ and $6 \%$ $\mathrm{Mn}$, as shown in Fig. 2d. It is shown by X-ray diffraction analysis (Fig. 2e) that the components of the ceramic layer are forsterite and alabandite $(\mathrm{MnS})$.

The film obtained with the $\mathrm{MgO}+1 \%$ Sr slurry is shown in Fig. 3a. Figure 3b presents the EDS spectrum obtained for the continuous layer of Fig. 3a. The continuous layer is relatively richer in oxygen, magnesium and silicon than the dark regions at the sub-layer, as shown in Table 2. The film formed with $\mathrm{MgO}+1 \% \mathrm{Sr}$ also presents regions with no forsterite particles, as shown by Fig. 3c. By EDS analysis it is possible to observe the presence of $\mathrm{Mn}$ and $\mathrm{S}$ in some thicker regions, such as at point 1 of Fig. 3c. This region presents $13 \% \mathrm{O}, 29 \% \mathrm{Mg}, 6 \% \mathrm{Si}, 25 \% \mathrm{~S}$ and $7 \%$ $\mathrm{Mn}$, as shown the EDS spectrum of Fig. 3d. The X-ray diffraction analysis, Fig. 3c, showed the presence of forsterite and alabandite on the surface of the sheet.

It can be observed that the chemical composition of the film formed after the annealing is independent of the chemical composition of the slurries used in this work. The ceramic film formed by $\mathrm{MgO}$ presents a thickness of ca. 1.1 $\pm 0.4 \mu \mathrm{m}$ while the film obtained with the $\mathrm{MgO}+1 \% \mathrm{Sr}$ presents a thickness of $1.2 \pm 0.5 \mu \mathrm{m}$. However, the ceramic films can be differentiated concerning their morphologies. Using image analysis, it was possible to evaluated the ceramic film concerning the relative volumes that the continuous layer and the forsterite particles present at the sub-layer. As shown in Figure 4, the film formed by the $\mathrm{MgO}+1 \% \mathrm{Sr}$ presented a smaller volume fraction of forsterite particles beneath the outermost surface layer. The data points shown in Figure 4 represent the average of 6 experiments of volume fraction evaluation. Each experiment was carried out in a field of $80 \mu \mathrm{m}$ of length.

The chemical composition depth profiles considering the elements $\mathrm{Fe}, \mathrm{Si}$ and $\mathrm{Mg}$, evaluated by GDS analysis are shown in Fig. 5 for the film obtained from the $\mathrm{MgO}$ slurry and in Figure 6 for the film obtained from the $\mathrm{MgO}+1 \%$ Sr slurry.

Usually, the intensity data from the GDS analysis is recorded as a function of time. The intensity $v s$. time data is then converted to intensity $v s$. depth by multiplication of the average sputter rate. So, the depths on the graphs shown on Fig. 5 and Fig. 6 are approximate. The intensity is proportional to the amount of element present in the plasma, which is controlled by the concentration of the samples and by the sputter rate. The intensities for Fe and $\mathrm{Mg}$ have been normalized for each sample (signal/5), so that the profiles could be presented on one scale.

Since the samples were prepared by heat treatment, the surface components diffuse gradually into the sample substrate $(\mathrm{Fe})$. It can be observed by Fig. 5 and Fig. 6 that the pure ceramic layers (when the Fe presents little signal) for

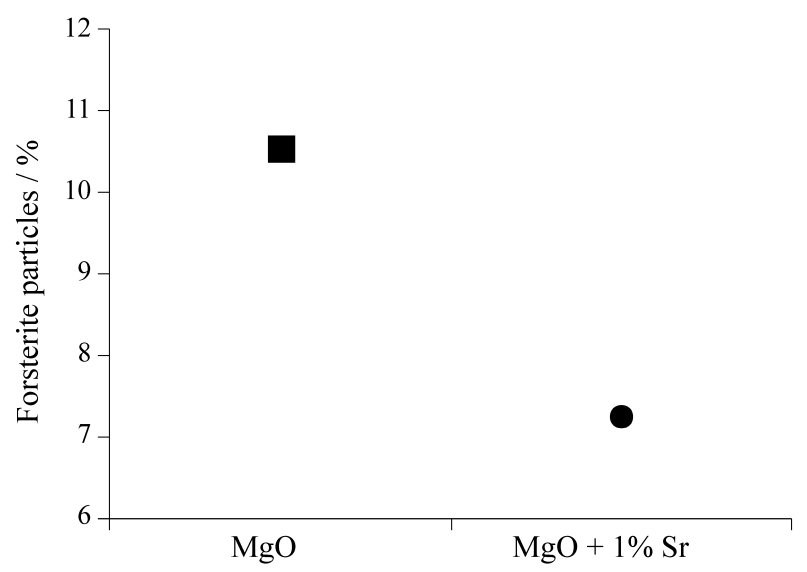

Figure 4. Volume fraction of forsterite particles in the film formed by $\mathrm{MgO}$ and $\mathrm{MgO}+1 \% \mathrm{Sr}$.



Figure 5. GDS intensity of $\mathrm{Fe}, \mathrm{Si}$ and $\mathrm{Mg}$ as a function of depth from the outermost surface for the sample coated with a $\mathrm{MgO}$ slurry. 


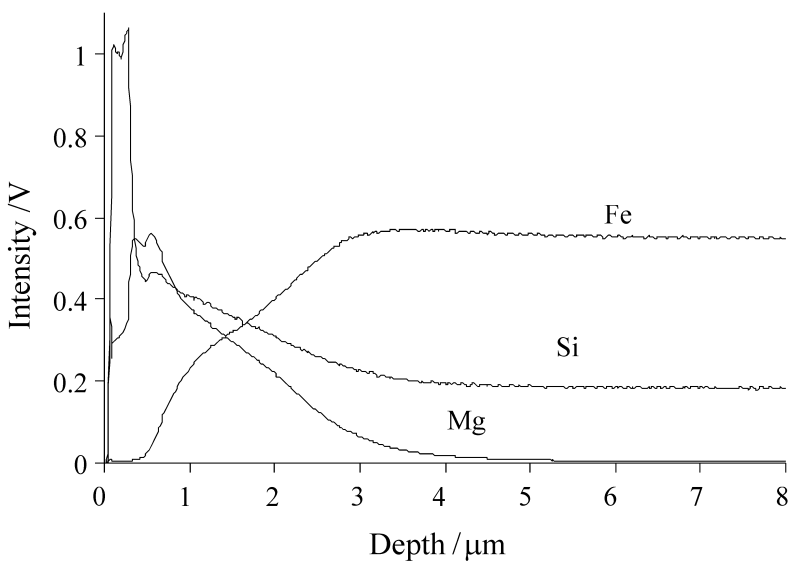

Figure 6. GDS intensity of $\mathrm{Fe}, \mathrm{Si}$ and $\mathrm{Mg}$ as a function of depth from the outermost surface for the sample coated with a $\mathrm{MgO}+1 \%$ Sr slurry.

the two samples are around $1 \mu \mathrm{m}$ thick. The depth profile also confirms the data shown in Fig. 4. The surface area tested on each sample is around $12.5 \mathrm{~mm}^{2}$ and the GD plasma sputters and atomizes this area in a layer-by-layer fashion. Thus, after $c a .1 \mu \mathrm{m}$, the result presented refers to the forsterite particles in a Fe matrix. In other words, the sample with smaller amount of forsterite particles in the sub-layer present a sharp decrease in the $\mathrm{Si}$ and $\mathrm{Mg}$ contents after a distance of $c a .1 \mu \mathrm{m}$, as shown for the film obtained from the $\mathrm{MgO}+1 \%$ Sr slurry in Fig. 6 .

The forsterite particles formed directly beneath the surface of a silicon steel sheet hinder the magnetic domain wall migration and cause a higher core loss of the steel sheet. Fig. 7 shows the core loss $(\mathrm{W} / \mathrm{kg}$ ) for the two types of samples used in this work. The coating with $\mathrm{MgO}+1 \%$ $\mathrm{Sr}$ presented a smaller core loss and also a smaller volume fraction of forsterite particles, according to Fig. 4.

\section{Conclusion}

It was possible to observe the influence of the magnesia containing strontium on the structure of the forsterite film formed on the grain oriented silicon steel. The use of $\mathrm{MgO}$ containing strontium reduced the amount of forsterite particles beneath the outermost ceramic layer. It was observed a reduced magnetic core loss with the use of the coating with $\mathrm{MgO}$ containing strontium.

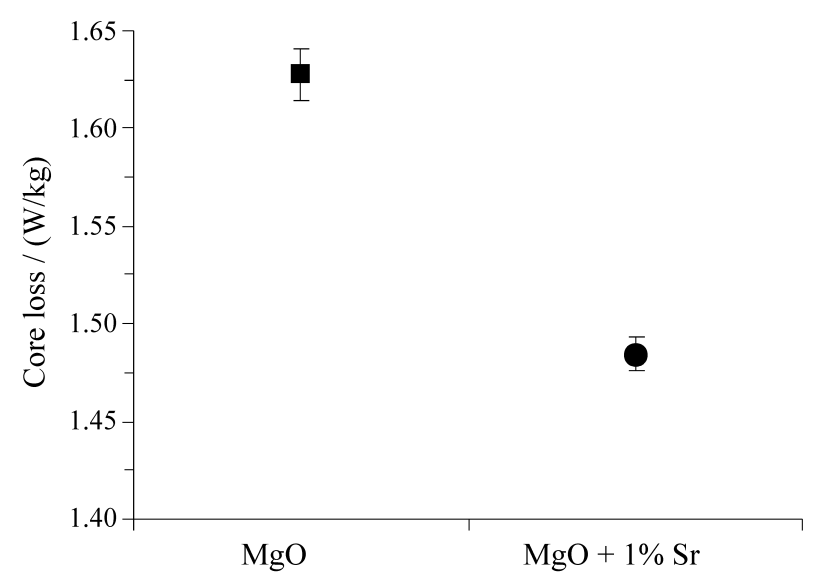

Figure 7. Magnetic core loss for steel sheets coated with $\mathrm{MgO}$ and $\mathrm{MgO}$ $+1 \% \mathrm{Sr}$ slurries.

\section{References}

1. Cunha, M.A. Cesar, M.G.M.M. IEE Transaction on Magnetics, v. 30, n. 6, p. 4890-4892, 1994.

2. Nippon Steel Corporation, Japan, Hiroaki Masui, Morio Shiozaki, Nobuyuki Takahashi, Hisashi Kabayashi, Takeo Nagashima, Shuichi Yamazaki, Hiroyasu Fujii. Grain Oriented Silicon Steel Sheet Having Excellent Primary Film Properties. Int. Cl6. B32B15/04. U.S. P. n . 5,565,272. 10 Jul. 1992; 15 Oct. 1996.

3. Kawasaki Steel Corporation, Japan, Nobuyuki Morito, Toshitomo Sugiyama, Yasuo Yokoyama, Toshio Ichida. Method of Forming an Insulating Film on a Grain Oriented Silicon Steel Sheet. Int. Cl3. H01F1/04. U.S. P. n . 4,242,155. 23 Apr. 1979; 30 Dec. 1980.

4. Cesar, M.G.M.M. Influência de Diferentes Tipos de Lama de Magnésia na Qualidade Física do Revestimento Primário e na Qualidade Magnética de um Aço Silício de Grão Orientado. Belo Horizonte, Master Thesis. Universidade Federal de Minas Gerais, 1993. 5. Armco INC., Wade S. Wright, Robin A. Murphy. Magnesium Oxide Coating for Electrical Steels and the Method of Coating. Int. Cl5. H01F1/04. U.S. P. $n$ 5,192,373. 12 Apr. 1991; 9 Mar. 1993.

6. Yamasaki, T. Transactions ISIJ, v. 9, p. 66-75, 1969. 